\title{
Implementation of Research-Based Learning Model at Indonesian Higher Education to Improve the Quality of Learning Process
}

\author{
Sukarno \\ Tidar University \\ Magelang, Indonesia \\ sukarno_edc@yahoo.co.id
}

\begin{abstract}
Many Indonesian universities have a similar vision of becoming research-based universities or research universities, and one of the missions is to conduct research-based learning (RBL). The study explored to develop the ideal model for RBL through R\&D design which involved (1) Research and Information Collecting, (2) Planning, (3) Developing Preliminary Product, (4) Preliminary Field Testing, (5) Main Product Revision, (6) Final Product Revision, (7) Dissemination and Implementation. The data were collected from 25 students and 5 lecturers of Tidar University by means of a questionnaire, and stuffing forms. Field notes were used to record constructive inputs for model development. Observation sheets were used to observe documents of planning, implementation, and evaluation of the learning process. Finally, interviews were conducted with all parties involved in planning, developing, testing and finalizing the model. All the data were then analyzed in accordance with R\&D analytical procedures to come up with credibility, dependability, conformability, and transferability of the findings. It turns out that the model of RBL is effective and needs to be fully implemented. It is also recommended that all parties be committed to excellence in support of the new model implementation in Tidar University or elsewhere.
\end{abstract}

Keywords: research-based learning, planning, implementation, evaluation

\section{INTRODUCTION}

Improving the quality of learning, in particular, the relevance and strategy used, is on the main agenda of today's European and American universities [1]. One of their priority agenda is to integrate two main academic activities, educational and research activities, by conducting Research-Based Learning (RBL).

Many Indonesian universities have a similar vision of becoming research-based universities or research universities. To realize the vision, one of the missions to be implemented is to conduct research-based learning. The goal of the RBL is to create and organize the learning process that leads to the analysis, synthesis, evaluation, and creation of activities as well as increasing the competencies of students (and lecturers) in terms of assimilation and application of science.
Although, in those universities, RBL has been declared and enforced for years, up to now, in most cases it has not been implemented in real terms. This happens mainly due to the lack of implementation in the field, including the lack of holistic understanding of the main concept of RBL.

At the moment, there are differences in the interpretation of RBL, among others, it is often interpreted as a learning activity in a research university by emphasizing the results of research as the materials on which lecturers' activities are based; and therefore, things should be supported by very sophisticated learning resources, such as the use of ICT.

In response to the above problems, a Research and Development (R\&D) has been conducted focusing on (1) identifying the existing RBL model, (2) constructing a model of RBL planning, (3) constructing a model of RBL implementation, (4) constructing a model of RBL evaluation, (5) identifying problems of RBL implementation, (6) testing the effectiveness of RBL.

Theoretically, research-based learning (RBL) is a multifaceted concept that refers to various learning strategies that combine research and learning. RBL is a learning approach aimed at helping students build intellectual and practical connections between research and their learning activities [2]. Meanwhile, Leeds University team argues that RBL is all the programs that develop students' research skills and give them the opportunity to execute those skills so that at the end of their program, under lecturers' guidance, they are able to carry out researches. Meanwhile, according to [3] RBL is a learning process that requires learners to be able to find, explore (develop knowledge) to solve problems encountered, and test the truth of that knowledge. The interaction of learning between students and lecturers is an active interaction. Lecturers act as facilitators and mediators in order to bring learners to achieve the expected competencies.

Based on the above three definitions, it can be concluded that research-based learning is a learning approach that provides students with opportunities to discover, explore, and develop knowledge and skills to solve problems encountered by establishing intellectual and practical connections between research and their learning activities. 
Ref. [4], there are two camps of the RBL approach which can be described as follows: "The first faction emphasizes research as the content or product to be referred to in the RBL, while the second camp emphasizes research as a process and/or a problem to be solved in learning activities. In the context of most Indonesian universities, orientation is preferred to RBLs that emphasize research as a process, not as a product".

\begin{tabular}{|l|l|}
\hline \multicolumn{2}{|c|}{ STUDENTS ARE PARTICIPANTS } \\
$\begin{array}{l}\text { Research-tutored } \\
\text { Engaging in research discussions }\end{array}$ & $\begin{array}{l}\text { Research-based } \\
\text { Undertaking research and inquiry }\end{array}$ \\
$\begin{array}{l}\text { EMPHA SIS ON } \\
\text { RESEARCH CONTENT } \\
\text { Learning about current research in the } \\
\text { discipline }\end{array}$ & $\begin{array}{l}\text { EMPHASIS ON } \\
\text { RESEARCH } \\
\text { PROCESSES AND } \\
\text { PROBLEMS } \\
\text { Research-oriented } \\
\text { Developing research and inquiry skills } \\
\text { and techniques } \\
\text { STUDENTS FREQUENTLY ARE AN AUDIENCE }\end{array}$ \\
\hline
\end{tabular}

Fig. 1. Two Camps of the RBL Approach [4]

Furthermore, the Association of American Colleges and Universities argues that one of the successful learnings at many American universities is the implementation of deep learning, not just 'surface-level learning'. Deep learning involves students actively competing for questions, observing, testing technology, and feeling the satisfaction that comes from successfully answering important questions and solving life problems. It is this statement that underlies the implementation of RBL in many American universities [5].

The National Commission on Educating Undergraduates in the Research University in the USA, known as The Boyer Commission, recommends research-based learning (RBL) as the standard of learning that is practiced in all universities. It is based on the philosophy of John Dewey a century ago: more learning is based on and determined by a mentored discovered process, not just the transfer of information [6].

By involving students in RBL, the lecturers will succeed in making the students have high valued competencies such as critical attitude, humble attitude because researchers always assume that there is no other purpose except 'truth', independent thinking, and express opinion clearly. The most important thing is that students learn to think critically-not to accept everything from lecturers as truth [7].

\section{METHODS}

\section{A. Data Collection}

This research and development consist of three grand phases, namely (1) need analysis, (2) model development, and (3) testing of model effectiveness. Five lecturers and twentyfive students participated in the study. Stuffing forms were distributed to the lecturers to obtain some information on the learning processes before and after RBL implementation. Meanwhile, questionnaires were distributed to the students to find their opinions about the effectiveness of RBL. Field notes were used to record constructive inputs for model development. Observation sheets were used to observe documents of planning, implementation, and evaluation of the learning process. Finally, interviews were conducted with all parties involved in planning, developing, testing and finalizing the model to come up with a new model of RBL.

\section{B. Data Analysis}

All the data that have been collected employing the above procedures were then analyzed, strictly adopting the analytical procedures of R \& D in order to come up with credibility, dependability, conformability, and transferability of the findings on the basis of which conclusion and recommendation were developed.

\section{RESULTS AND DISCUSSION}

\section{A. Findings}

\section{1) General Findings}

Three lecturers expressed strong agreements to the development of new RBL paradigm while the other two stayed neutral. They found out that RBL enabled learning processes to be updated on a regular basis to catch up the development and innovation of new technology in terms of relevance to the course contents. In the past, on the contrary, teaching materials were oriented to textbooks delivered in conventional ways. Meanwhile, the majority of the students (87\%) found it useful and challenging with respect to the implementation of RBL, $10 \%$ simply agreed, and the other $3 \%$ remained neutral. Thus, RBL has a legal standing to be continued and even developed.

\section{2) Proposed Model of RBL}

The proposed model of RBL is that RBL is carried out in one cycle consisting of three phases, namely (1) planning, (2) implementation, and (3) evaluation as represented below: 


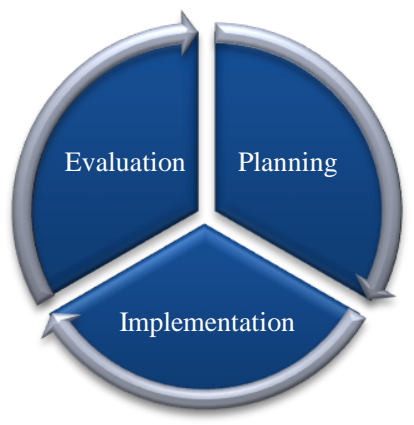

Fig. 2. RBL Cycle in Three Phases

In the planning phase, all parties involved (lecturers, students, university management) are committed to excellence in support of the implementation of RBL, some of which include the lecturers' research sustainability (all researchers conducted in line with the university research road-map), welloriented students with respect to the implementation of RBL and the university's complete resource facilities.

In the implementation phase, it should be noted that RBL is actually the realization of Student-Centered Learning (SCL) by integrating research into the learning process in which one cycle as above can be illustrated in terms of "The Eight Strategies for Successfully Linking Teaching-Learning and Research", the pattern developed [2], consisting of.

1) Enriching teaching materials with lecturer research results;

- Dealing with the on-going materials by introducing the lecturer's research results related to the current discussion

- Making the students work in small groups to discuss (1) central theme of the research, (2) research process and analytical procedures, (3) conclusion and values of study in relevance to the current learning materials.

2) Using the latest research findings and tracking the history of recent developments;

- Discussing the findings from the literature review to support relevant materials in order to learn the dynamic development of science in historical perspectives.

- Empowering the students with knowledge that the current policies and practices can be developed as a unity of dynamic development of science including the distinctive national and international experts (figures) who focus on the subject in question.

3) Enriching learning activities with contemporary research issues:

- Encouraging the students' learning activities in accordance with contemporary research issues in such a way that researchers are located within a specific research community.

- Highlighting the importance of previous relevant research to develop current research
4) Teaching research methodology in the learning process;

- Introducing research methodology during the learning process to the students for them to, later on, facilitate their own researches

5) Enriching the learning process with small-scale research activities;

- Equipping the students with experiences in conducting small research activities in support of their skills in doing their own research projects;

- Anticipating the students' future research constraints, such as choice of topics, methods, etc.

6) Enriching the learning process by involving learners in institutional research activities;

- Making the best use of research outputs (and outcomes) for the development of learning activities;

- Training the students to value researchers as academic achievements;

7) Enriching the learning process by encouraging students to feel part of the research culture in the faculty/department/study program;

- Giving the students opportunities to develop their own scientific entities in conducive academic atmospheres that enable them to be creative in their own major;

8) Enriching the learning process with the values that must be owned by researchers.

- Appropriating the students' academic behavior and attitudes toward scientific development in the world of education in a digital and global era.

In line with the above strategy, one of the patterns that can also be referred to is that, which is applied at the University of Illinois at Urbana-Champaign known as 'The Seven Steps of Creating Students as Consumer of Knowledge Being Knowledge Producers' is as follows:

- Students are given a quick overview of basic facts, terminology, and ideas related to certain disciplines;

- Students study the research findings through lectures or readings in related disciplines;

- Students discuss and criticize the findings, including self-review of literature reviews or summaries;

- Students study several research methods, and engage in the limited application of such approaches such as statistical analysis as homework;

- Students present it in class;

- Students engage in simple research projects designed for them, e.g. replication of previous research;

- Students are involved in original research projects designed for lecturers and students.

The following are the activities directed by [8] for students to implement the RBL: 
- Interviewing prominent, internal or external campus research figures, in the field,

- Studying and discussing scientific research articles;

- Writing a review of a scientific research article, presenting it in class and discussing it;

- Designing research proposal according to field of study;

- Collecting and analyzing data to answer research questions;

- Writing a paper about a person's research;

- Making your own research poster or someone;

- Writing articles in a journal according to each discipline;

- Making a report within the research block;

- Writing a reflective assessment of the learning process of yourself or other students.

The evaluation phase gives an opportunity to evaluate all the activities performed in RBL paying particular attention that RBL is flexibly implemented in accordance with what prominent factors attributed to the lecturers, students and university management. In the process of evaluation, several techniques can be used, such as questionnaire, in-depth interviews, observation in order to have a general feedback for all parties to improve the implementation of RBL in the future with a larger scope. In case of discrepancies, it is also possible to review the RBL cycle, starting from planning, implementation, and evaluation, to see if any of the phases has experienced potential problems.

\section{B. Discussion}

RBL is a relatively new model of learning activities. There are a number of constraints for the higher institution to fully implement this new model. One of the inevitable problems is that at one time or another lecturer may not have the chance to conduct researches on a regular basis due to professional and financial problems. It is therefore important to suggest that the institution provide an increasing amount of fund allocated for research. Lecturers should also update themselves with respect to the mastery of research methodology, coursework materials, and teaching competencies.

Finding out research topics in accordance with the students' course of study is not easy at all and therefore may create another problem. It is really dilemmatic; the research roadmap and the study program curriculum must be synchronized without reserve in order for the research topics to be in line with the topics within the curriculum. In other words, the research topics must be adapted to the curriculum or the curriculum must be adapted to fit the research topics. The decision on which one to adapt requires the establishment of policy at all levels of management.

At the university level, for example, the vice rector for academic affairs must have a clear vision of the university goal, as a research university, and therefore must also be able to coordinate activities with the dean of each faculty in terms of the curriculum of each study program. Likewise, it is also important that the research division provides a research roadmap which can accommodate possible research topics in compliance with the study programs in each faculty within the university. There must be a grand design for both research roadmap and curricula to achieve one unified goal of the university, which can be represented in the Fig.3.

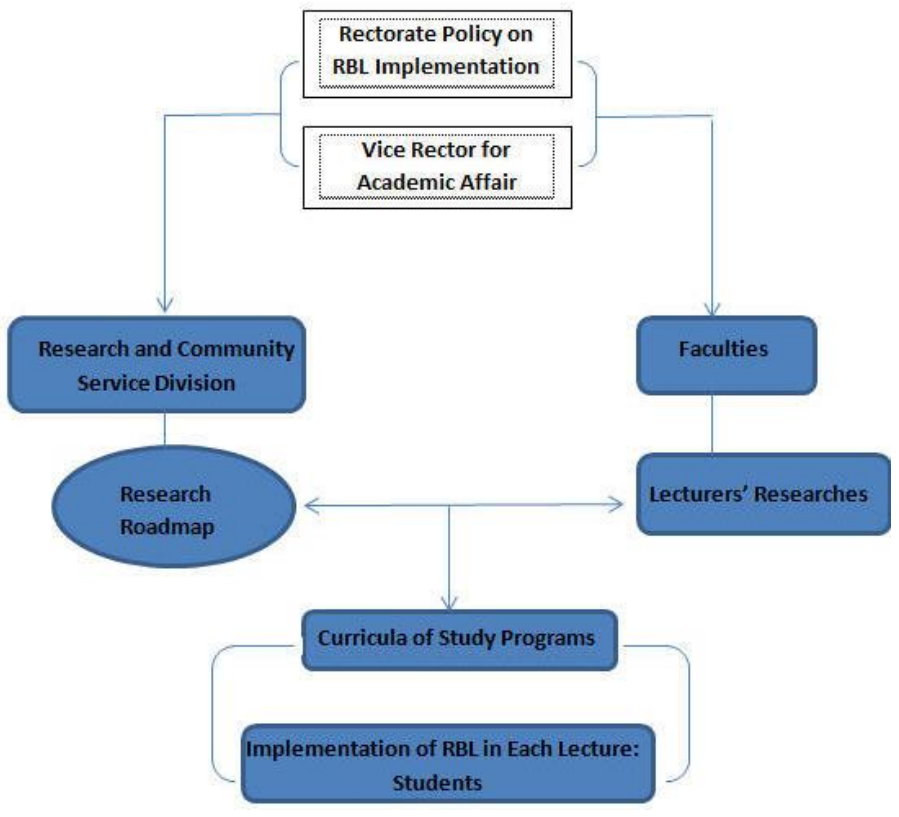

Fig. 3. Model of RBL Implementation

Fig.3. above indicates that RBL implementation is under the Rectorate Policy in close association with the Vice Rector for Academic Affairs functioning as the coordinator for both Research and Community Services Division and the Faculties within the University. It should be noted that the lecturers' researchers and the research roadmap are well synchronized according to the topics in the curriculum of each study program in order for RBL to be well implemented.

The implementation of RBL at most of the Indonesian universities should, therefore, be done systematically, gradually, continuously, involving all related parties, especially university leaders, faculties, departments, study programs, lecturers, students, and education personnel. The following are recommended activities for RBL to be implemented optimally and deliver results according to the above objectives and benefits.

- Establishing a Learning Development Center at the university level in charge of the development plan, implementation, evaluation, and management of RBL, as well as conducting training for lecturers (see Fig. 3 for the illustration of how each component supports the program;

- Increasing the insight and competence of research of all lecturers and facilitating the improvement of quantity and quality of research at university, faculty, department/study program level; 
- Establishing research groups in study programs/majors according to the subjects that are taught mainly to identify and provide the results of research and other lecture materials in each field of science;

- Providing adequate services, especially libraries, which support the provision of references and information for lecturers and students;

- Providing supporting facilities and infrastructure, e.g. 'RBL Corner', and facilitate lecturers and students to carry out various studies and/or research;

- Reviewing and revising pro-RBL curriculum, then organizing RBL planning workshops with key syllabus, lesson plan, materials, and RBL evaluation products for all lecturers;

- Implementing cooperation (benchmarking) with other universities that have best practices to accelerate the implementation of the RBL;

- Facilitating an RBL-based learning innovation grant program (textbook) at the university as well as faculty level;

- Facilitating dissemination of best practices internally at university, faculty, department/study program level;

- Conducting continuous and continuous focused group discussions in the context of evaluation and revision of the planning and implementation of the RBL system.

The current study has explored, designed and implemented RBL for one semester period. The final results of the questionnaire and interviews (with the students) indicate that RBL is effective, challenging and full of creativity on the part of the lecturers and the students.

The lecturers are always challenged to produce quality research in accordance with the central research roadmap to support the topics offered in the study programs. In this respect, research is conducted on purpose to support the institution as a research university. The students are very much encouraged to critically scrutinize the findings of relevant research on their fields of studies. At the same time, they also learn how to conduct researches in a narrow scope. This has given invaluable experiences to support them, later on, when they have to write a research report for their final project. Most importantly, topics in the classroom are made to discuss contemporary issues-blended materials of the research findings (by the lecturers) and the teaching materials offered in the study programs.

\section{CONCLUSION}

The model of RBL implementation has been discussed with respect to the possible activities that support the program. As an innovation that combines learning and research, RBL prioritizes the significance, attractiveness, quality, and relevance of learning. Many of the world's leading universities make RBL a leading agendum in improving their classes. At the moment Tidar University as a developing university is very appropriate to make the RBL as the primary mission in an attempt to reach the university's goal as a research university. In this respect, the university has to work to overcome possible constraints.

For RBL to be implemented optimally, the first thing that is very important to do is to build a system of development, implementation, monitoring, and evaluation of RBL. Equally important is to build awareness and competence of all interested parties, especially the lecturers to plan and implement it appropriately. Despite the fact that the current study is a simple portrait of RBL implementation in Tidar University, the findings may also be applied elsewhere with or without modification.

The saying goes 'There is no best method in the world, only those that fit the situation,' RBL certainly has some advantages as well as shortcomings. Therefore, the effort to design and implement it needs to be balanced with an adequate monitoring, evaluation, and revision system.

\section{REFERENCES}

[1] European University Association. 2015. Trends 2015: Learning and Teaching in European Universities. Brussels: European University Association. A free electronic version of this report is available through www.eua.be

[2] Griffith Institute for Higher Education. 2008. Research-Based Learning Strategies for Successfully Linking Teaching and Research. University of Griffith

[3] Wardoyo, Sigit Mangun. 2013. Research-Based Learning.Jakarta: Akademia

[4] Healey, M. 2009. Linking Research and teaching: Exploring disciplinary spaces and the role of inquiry-based learning. Reshaping the University: New Relationships between Research, Scholarship, and Teaching. R. Barnett. McGraw Hill. Open University Press

[5] Association of America Colleges and Universities, 2009. High-Impact Educational Practices; What they are, who has access to them, and why they matter. Washington DC: Association of America Colleges and Universities. www.aacu.org

[6] Boyer Commission on Educating Undergraduates in the Research University. 1998. Reinventing undergraduate education: A blueprint for America's research university. New York: the State University of New York or Stony Brook

[7] Elen, J., Lindblom-Ylane, S. \& Clement, M. 2007.Faculty developmen in research-intensive universities: The role of academics' conceptions on the relationship between research and teaching, International Journal for Academic Development 12 (2) 123-139

[8] Dekker, H. and Sylvia Wasarie Wolf. 2016. Re-inventing Research Based Teaching and Learning. Paper prepared for presentation at the meeting of the European University Association: Brussels, 5 December 2016 